\title{
LA REFORMA DEL PROCEDIMIENTO. VIEJOS PROBLEMAS NO RESUELTOS Y NUEVOS PROBLEMAS NO TRATADOS
}

\author{
José María Baño León \\ Catedrático de Derecho Administrativo \\ Universidad Complutense de Madrid \\ jmbleon@jmbleon.com
}

\section{I.- LA EXPOSICIÓN DE MOTIVOS}

El Proyecto de Ley de Procedimiento Administrativo Común (en adelante PLPAC) dice querer establecer "una regulación completa y sistemática de las relaciones ad extra entre las Administraciones y los administrados". Sin embargo, al explicar cuál es la materia sobre la que versa, se refiere "al ejercicio de la potestad de autotutela (...) en cuya virtud se dictan actos administrativos que inciden directamente en la esfera jurídica de los interesados, como en lo relativo al ejercicio de potestad reglamentaria y la iniciativa legislativa. Queda así resumido en un cuerpo legislativo único -asevera el texto- la regulación de las relaciones ad extra de las Administraciones con los ciudadanos como leyes administrativas de referencia que se ha de complementar con todo lo previsto en la normativa presupuestaria..."

Basta esta paladina confesión del Proyecto de Ley para comprender que la concepción de la ley no dista mucho de la que sostuvo la aparición de la Ley de Procedimiento Administrativo de 1958. Cabe entonces preguntarse si la arquitectura de la Ley del 58, que en lo sustancial mantiene la LRJPAC vigente y el PLPAC, es adecuada para la Administración Pública de nuestros días cuyos cometidos ni son comparables a los de la Administración de los años cincuenta ni a las necesidades de una sociedad bien distinta a la de aquella época.

Esta primera conclusión, que resulta de la explicación misma que el PLPAC contiene, debe ser ahora desarroIlada atendiendo al contenido de la ley. Y para ello parece oportuno contrastar lo que una ley de procedimiento debiera contener con lo que trata.

Parece, en efecto, de cara a las necesidades que la Administración de nuestros días debe atender, que la Ley de Procedimiento exige una profunda reforma, más allá de la incorporación de la Administración electrónica.

La Administración electrónica -frente a lo que el Proyecto cree ingenuamente- no muta la naturaleza de las cuestiones que el procedimiento administrativo debiera abordar, a saber:

a) Una ley de procedimiento debe ocuparse de lo que la Administración hace en toda su amplia variedad, y no sólo de una de sus formas, el acto administrativo y las disposiciones de carácter general.

b) Una ley de procedimiento debe asegurar una protección eficaz de todos los derechos afectados por la acción pública, no exclusivamente de los derechos del titular de una solicitud. Justo cuando la interpretación constitucional es más receptiva a la consideración de los fines constitucionales como normas de protección, la regulación legal minusvalora los derechos de quienes invocan derechos ambientales o de seguridad frente a la libertad de empresa.

c) Una ley de procedimiento debe garantizar ante el ciudadano que existe una persona responsable del procedimiento y separar estrictamente la responsabilidad de la Administración y la función auxiliar de las empresas que colaboran con la Administración.

d) Una ley de procedimiento, en fin, debe instaurar garantías y principios básicos a todos los procedimientos, cualquiera que sea la Administración actuante. Las especialidades de cada procedimiento no deben quebrar con el mandato constitucional (art. 149.1.18 ) de un procedimiento común.

Como se explica a continuación, el PLPAC no contiene reforma alguna de calado; sigue, en lo esencial la LPA de 1958, sin afrontar ninguno de los grandes retos actuales. 


\section{II.- VIEJOS PROBLEMAS NO RESUELTOS}

\section{1.- ¿Un procedimiento “común”?}

El artículo $149.1 .18^{\text {a }}$ CE atribuye la competencia al Estado sobre las bases del procedimiento administrativo común a todas las Administraciones Públicas. El Tribunal Constitucional ha interpretado esta competencia como expresión de los principios o garantías básicas del procedimiento (SS. 227/1988, FJ8; 130/2013, FJ7). Lo cual parece demandar que los contenidos de una ley de procedimiento general afecten a todas las Administraciones Públicas, sin perjuicio de las especialidades de los concretos procedimientos. En la STC 166/2014, que declara la inconstitucionalidad de una norma catalana por diferir en el cómputo del plazo de caducidad de los procedimientos, recuerda el Tribunal con razón, "que naturalmente los procedimientos especiales por razón de la materia que regulen las Comunidades Autónomas de acuerdo con sus competencias deben siempre «respetar» ese modelo o estructura general definidos por el Estado (... ), pues de otro modo éste no cumpliría su función de ser el procedimiento administrativo «común»" (FJ5, d).

Es el caso, sin embargo, que la proyectada nueva ley de procedimiento, mantiene impertérrita el carácter supletorio de la ley respecto de la Hacienda Pública y de la Seguridad Social, lo que resulta incompatible con su pretendido carácter común.

Una vez más la aspiración de la Hacienda (y de la Seguridad Social) a un tratamiento autónomo se impone sobre la racionalidad administrativa. Pues, en efecto, es difícilmente comprensible que lo que es común a todos los procedimientos, no lo sea para determinados órganos de la Administración del Estado. No se trata de ignorar las especialidades de ciertas ramas de la Administración, se trata de imponer un esquema racional, en el que la ley de procedimiento se ocupe de los principios generales garantizando un tratamiento mínimo común. Una de dos, o la ley de procedimiento no tiene carácter general, o la Hacienda Pública y la Seguridad Social, no se inspiran en los principios y garantías generales del procedimiento administrativo. Vale decir: las exigencias recaudatorias se imponen sobre las garantías del procedimiento general, que deja de ser común en estas materias. La Disposición adicional primera del proyecto de ley de procedimiento no sólo incurre en este defecto tradicional, sino que lo incrementa, al dar carácter supletorio a la ley respecto de los procedimientos sancionadores más importantes (tributos, aduanas, infracciones de orden social, tráfico y seguridad vial y extranjería) así como, en general, los procedimientos de extranjería y asilo, de manera que el carácter principal de la ley se desnaturaliza absolutamente. Los procedimientos especiales del Estado priman sobre los generales. La Ley de Procedimiento no establece, pues, lo común a todos los procedimientos, sino sólo lo común a algunos procedimientos. El Estado que impone lo común a las demás Administraciones se desvincula a sí mismo de lo que considera básico.

\section{2.- El régimen de recursos o la victoria del inmovilismo}

También es decepcionante el régimen de recursos instalado en un inmovilismo, que no tiene otra justificación que mantener el "statu quo" que solo beneficia a la Administración. El mantenimiento del recurso obligatorio de alzada, sin modificar el régimen jurídico de los órganos llamados a resolverlos, supone un claro atentado a la funcionalidad del recurso administrativo como filtro previo al contencioso-administrativo. El ejemplo del Tribunal Central de recursos en materia de contratación pública demuestra que es esencial conceder independencia funcional a los órganos de control sobre los de gestión.

En la administración en masa (recursos por sanciones de tráfico, por ejemplo), un recurso administrativo sencillo y gratuito ante órganos funcionalmente independientes, es la única forma posible de control efectivo de la Administración.

En la mayoría de casos, el acceso a la jurisdicción ni está justificado ni es operativo por los costes judiciales (honorarios de abogados y procuradores, condena en costas). De modo que un recurso administrativo operativo es la única justicia posible para cientos de miles de particulares.

Sorprende, pues, la falta de ambición del proyecto de ley en un extremo tan sensible, máxime cuando ya existían estudios bien documentados sobre la oportunidad de generalizar en nuestro derecho este tipo de órganos en algunos casos'.

\section{3.- El régimen de la revisión de oficio y la primacía del Derecho de la Unión Europea}

Una cuestión central tratada desde antiguo es el régimen de revisión de los actos administrativos firmes. La ley mantiene el nervio de la regulación de 1958, prescindiendo de la revocación de actos por motivo de oportunidad, que ocupa un papel central en el Reglamento de Servicios de las Corporaciones Locales de 1958, apartándose

1 SANTAMARÍA PASTOR, J.A: “Los controles sobre la actuación de las Administraciones Públicas” en SAINZ MORENO, F. (Dir.): “Estudios para la reforma de la función pública”. INAP. Madrid 2004, pp. 190-191. 
así de un tratamiento exhaustivo de la revisión de actos administrativos, tanto por motivo de legalidad como por motivo de oportunidad.

Por otra parte, pese a la denuncia que luce en el Informe del Consejo de Estado de 14 de febrero de 2008 (pág. 228 y ss.), tampoco se ocupa la reforma del régimen de los actos declarativos de derechos contrarios al Derecho de la Unión Europa, supuesto que hubiera debido merecer alguna reflexión en el proyecto de ley, a juzgar por los numerosos problemas que plantea en la práctica, pues por regla general la disconformidad al Derecho de la Unión de un acto administrativo no es constitutiva de nulidad de pleno derecho sino de anulabilidad.

\section{III.- PROBLEMAS NUEVOS NO TRATADOS}

\section{1.- La incorporación de nuevos derechos procedimentales}

\section{a) Excurso sobre el procedimiento electrónico y el ejercicio de los derechos}

El proyecto es reiterativo en la insistencia en el procedimiento electrónico importando los preceptos de la Ley $11 / 2007$, de 22 de junio. Y con justo título proclama el derecho a comunicarse con la Administración Pública a través de un "Punto de Acceso General electrónico de la Administración” (artículo 13.a)) y el derecho a conocer el estado de la tramitación y obtener copias de la documentación disponible en el SAG o en la sede electrónica que corresponda. También contiene el PLP (art. 70) una mención al expediente electrónico.

No obstante debe destacarse que, en el ámbito electrónico, las garantías de los particulares se juegan más en la normativa técnica y en la capacidad de accesibilidad del "software" utilizado que en la ley. La ley debe establecer los principios, en realidad los fines, que el procedimiento electrónico, debe alcanzar. Y entre ellos se echa de menos el de inteligibilidad de la información. No basta con que la información electrónica sea accesible, sino que debe ser inteligible para el ciudadano corriente. La experiencia del tratamiento de la información en muchos procedimientos electrónicos es decepcionante y opaca incrementado la dificultad de acceso a la información bajo la capa de una aparente transparencia electrónica.

Ese objetivo de inteligibilidad es inexorable para garantizar los derechos del ciudadano común y sobre el mismo deberían articularse el estándar técnico. Pues, frente al empeño de la ley por establecer reglas que disciplinen el procedimiento electrónico en esta materia, la única garantía efectiva es que el "software" correspondiente permita un acceso sencillo y un manejo simple de la información.

\section{b) Derechos de defensa. Extralimitación de la ley en el tratamiento del deber de colaboración y de las medidas provisionales}

Sin embargo, hay otros derechos procedimentales cuya eficacia si depende, en gran medida, del tratamiento legal. Se podría esperar de una moderna ley de procedimiento que reconociera alguno de los derechos que son comunes en todo el ámbito de la Unión Europea, fruto, sobre todo, de la jurisprudencia:

\section{Derecho a no declarar contra símismo}

El primero de estos derechos, es el de no declarar contra sí mismo, cuya vigencia ha sido reconocida tanto por la jurisprudencia del TJUE como del TEDH.

Parece claro que una ley de procedimiento debiera deslindar este derecho de la entrega de documentos, precisar sus límites, en resolución. Nada de esto contiene la ley que, en cambio, construye una obligación general de colaboración con la Administración, difícilmente admisible.

Una ley general de procedimiento establece el marco general de derechos y obligaciones del interesado y dibuja, también con carácter principal, las potestades públicas. Lo que no cabe a mi juicio, es que la ley imponga deberes generales a los ciudadanos, que equivalen a un reconocimiento general e irrestricto de potestades administrativas, sin la intermediación de la ley especial para cada procedimiento concreto. Lo que puede estar justificado en una ley de defensa de la competencia, puede no estarlo con carácter general. Si, con razón, la doctrina ha impugnado la posibilidad de una teoría general de los deberes constitucionales, más allá de supuestos específicos previsto en la Constitución misma o en la Ley, con tanta o mayor razón ha de rechazarse que una ley ordinaria general pueda construir un deber general de colaboración con la Administración o que, en otro plano, sea admisible el reconocimiento genérico de medidas provisionales (que se asimilan además a las judiciales de la LEC) sin que cada ley específica concrete estas potestades. Ni el art. 18 ni el art. 56 PLPAC superan el examen de constitucionalidad.

El art. 18, tras decir que "Las personas colaborarán con la Administración en los términos previstos en la Ley que en cada caso resulte aplicable”, obliga a falta de previsión expresa de la Ley; a facilitar a la Administración “los 
informes, inspecciones y otros actos de investigación que requieran para el ejercicio de sus competencias, salvo que la revelación de la información solicitada por la Administración atentara contra el honor, la intimidad personal o familiar o supusieran la comunicación de datos confidenciales de terceros de los que tengan conocimiento por la prestación de servicios profesionales de diagnóstico, asesoramiento o defensa, sin perjuicio de lo dispuesto en la legislación en materia de blanqueo de capitales y financiación de actividades terroristas".

Además de no prever como límite el carácter confidencial de la información solicitada (por ejemplo, la contabilidad de la empresa), esta obligación genérica atenta a la reserva de ley a la seguridad jurídica en la medida en que se inviste a la Administración para cualquier procedimiento de una potestad tan genérica no se cumple con los requerimientos mínimos de la reserva de ley, que exige que el legislador regule los aspectos esenciales de la materia de que se trate.

Más grave aún es el $n^{\circ} 2$ del citado art. 18, cuando obliga a cualquier interesado a proporcionar a la Administración los datos que permitan identificar a otros interesados. Esta obligación puede tener sentido en algunos procedimientos concretos, como el de la seguridad vial, que el Tribunal Constitucional ha respaldado. Pero es abiertamente desproporcionado imponerlo como una obligación genérica, cualquiera que sea el procedimiento. Probablemente se trate de un deber sin sanción. Pero en la forma en que está redactado puede habilitar a la Administración a ordenar esa colaboración, con la consiguiente desobediencia si no se cumple la orden. En este último sentido resulta, a mi juicio, inconstitucional por afectar a la garantía material de la reserva de ley.

En cuanto a las medidas provisionales, se llega a idéntica conclusión. Al atribuir una potestad genérica a la Administración para imponer cualquier medida cautelar -incluso antes de la incoación del procedimiento- en cualesquiera procedimientos el PLPAC está vulnerando la reserva de ley que impide proscripciones de la libertad de manera genérica para cualesquiera fines.

Si la remisión genérica de la ley al reglamento está vedada con carácter general, con mayor razón lo está la remisión incondicionada de la ley al acto de cualquier Administración para ordenar medidas provisionales tales como suspensión temporal de actividades, prestación de fianzas, embargo preventivo, etc. La remisión que el precepto hace a la Ley de Enjuiciamiento Civil, resulta así más incompatible, pues la Administración no es “iudex inter partes", sino servidora de intereses generales. Investir de las mismas potestades a la Administración que al Juez resulta desproporcionado y preocupante, habida cuenta del carácter inmediatamente ejecutivo de medidas que pueden ocasionar perjuicios difícilmente reparables. Sólo la ley especial, en cada sector concreto, pueden establecer las medidas provisionales idóneas. En ningún caso la Administración puede estar investida con carácter genérico de poder para adoptar todo tipo de medidas, sin afectar gravemente a la libertad y a la reserva de la ley, como ya se ha dicho.

No se entiende la razón de esta generalización de una potestad exorbitante (que nadie había reclamado), frente al medido tono que emplea el vigente art. 72 LRJPAC, que remite a cada ley singular la ponderación de las medidas provisionales a adoptar.

Podría concluirse en este punto con el siguiente aserto: en vez de instaurar los derechos y garantías básicos a cualquier procedimiento, la ley habilita a la Administración con potestades genéricas para cualquier procedimiento, lo que supone traspasar los fines propios de una ley procedimental, pues solo cada ley específica puede establecer la adecuada ponderación entre los derechos de los particulares y las potestades administrativas.

\section{El tratamiento confidencial de la información}

Tampoco existe novedad de bulto en el tratamiento de la información. En un mundo en el que la Administración interviene cada vez más internamente en relaciones multipolares, una ley de procedimiento debe atender no sólo al secreto profesional industrial, sino a la información sensible de las empresas.

La posibilidad misma de que, en ciertos procedimientos, la documentación sea expurgada para que el derecho de defensa de la parte opuesta sea compatible con la protección del secreto comercial o industrial, está prevista en la LDC, pero merecería un tratamiento en el procedimiento común, al tratarse de una garantía básica, que no tiene una regulación general en nuestro ordenamiento.

\section{La confidencialidad de la relación entre abogado y cliente}

Otro aspecto capital no tratado en la ley es la confidencialidad de la documentación trabada entre abogado y cliente, a efectos de que sea accesible a la Administración. Hay una jurisprudencia en el ámbito del Derecho de la Competencia europeo que podría haber inspirado la regulación de esta cuestión nada baladí, esencial tanto en la inspección como en el procedimiento sancionador. 


\section{2.- Las formas de la actividad administrativa no se reducen al acto administrativo y al reglamento}

\section{A) El acto administrativo no cubre toda la actividad de la Administración}

El artículo 1 PLPA es muy representativo de la cortedad de miras de la reforma: "La presente ley tiene por objeto regular los requisitos de validez y eficacia de los actos administrativos, al procedimiento administrativo común a todas las Administraciones Públicas...".

Nadie discute la importancia del acto administrativo como figura central del Derecho Administrativo; pero hay otras formas de la actividad administrativa de singular importancia, el plan y el contrato, y existe toda una actividad de supervisión o inspección de la administración, además de la actividad no formalizada, que no merece ni un solo precepto en el proyecto.

\section{B) La inspección administrativa}

Comenzando justamente con un sector cada vez más importante de la actividad administrativa, no necesariamente ligado a un procedimiento formalizado, se echa en falta en el PLPA un tratamiento general de la inspección.

El asunto fue objeto de reflexión en la Comisión para la reforma de la Administración presidida por Fernando Sainz Moreno. En la publicación de los resultados de los trabajos de la Comisión hay abundantes propuestas que no han sido tenidas en cuenta en el Proyecto 2.

Una de ellas era justamente la necesidad de regular el marco general de la inspección administrativa, en provecho de la eficacia de la misma y de la garantía de los derechos de los particulares. Las particularidades de la inspección se ignoran abiertamente en el proyecto de ley, pegado, como ya se ha dicho, a una visión del procedimiento miopemente enfocado exclusivamente al acto administrativo.

C) La suspensión administrativa y las nuevas relaciones entre la administración y los ciudadanos. Un asunto capital no tratado en la ley.

La transposición de la Directiva de Servicios al vigente art. 71.bis LRJPAC ha hecho emerger un viejo problema dogmático de indudable relieve práctico: el desplazamiento parcial del acto administrativo como eje teórico de explicación del vínculo que une a la Administración y a los particulares.

Si el control público de determinadas actividades privadas se desplaza de la autorización previa a la fiscalización "a posteriori" resulta fácil concluir que el espacio de nexos entre el particular y la autoridad pública no está cubierto por el acto administrativo, sino por una relación jurídico-pública que la ley construye al someter determinas actividades particulares al control administrativo. No se trata de un fenómeno nuevo. Basta pensar en la relación jurídico-tributaria en la que los actos del particular quedan sujetos al control "a posteriori" de la Administración, o en el entramado de relaciones que une a los particulares con la seguridad social o con la Administración asistencial o sanitaria, no reductibles a la figura del acto administrativo.

Tampoco, desde el punto de vista dogmático, el asunto es nuevo; fue objeto de un apasionado debate durante los años setenta en Alemania, y no ha faltado en España intentos de inclusión sistemática de la figura de la relación jurídico-administrativa en la manualística de la disciplina.

La extensión, sin embargo, de la técnica del control "a posteriori” plantea problemas de tal calado que resulta imprescindible abordar en una ley de procedimiento a la altura de nuestro tiempo. Los resumimos ahora en tres aspectos:

a) Se ha destacado mucho -con razón- la inseguridad jurídica que produce al empresario su sujeción "sine die" al control de la Administración. Una ley de procedimiento debe establecer mecanismos de compensación que deben ser cuidadosamente desarrollados.

Por una parte, la limitación de la revocación temporal de la situación objeto de la comunicación puede incrementar la seguridad jurídica; por otro, el ejemplo de situaciones paralelas como la de la potestad de restablecimiento de la legalidad urbanística, cuyo plazo de caducidad ha fomentado objetivamente la ilegalidad nos advierte de los peligros de la fórmula. Habría, pues, que barajar soluciones intermedias en los que el transcurso del plazo, si bien no limitara la potestad de revocación frente a ilegalidades graves, si condujera a la indemnización de los daños y perjuicios causados, incentivando así el cumplimiento tempestivo por una Administración de su potestad de inspección, exceptuado siempre el supuesto de engaño o fraude en la solicitud ("exceptio doli").

2 REBOLLO PUIG, M.: "Propuesta de regulación general y básica de la inspección y de las infracciones y sanciones administrativas", en Sanz Moreno, F. (dir.), op. cit. págs. 447-460. 
b) Se han destacado menos los límites que los derechos de otros interesados, en la relación jurídica de supervisión, imponen a estas técnicas, bien en el sentido de eliminarlos en determinados casos o modularlas.

En efecto, la libertad de empresa no es el único derecho concernido por la actividad económica, cuando incide en el ámbito de otros derechos protegidos por el ordenamiento, como la seguridad de las personas, el derecho al respeto a las normas ambientales o a la seguridad ${ }^{3}$. No por casualidad la Directiva de Servicios establece que la protección de los consumidores, el urbanismo y el respeto de la normativa ambiental, son límites que justifican las autorizaciones previas o, en todo caso, permiten que haya un periodo de "vacatio" entre la comunicación del interesado y el despliegue de sus efectos.

La consideración de estos derechos, que no son en realdad derechos reaccionales de terceros, sino derechos principales que el ordenamiento debe proteger con la misma intensidad, es inexorable en un Estado de Derecho. El asunto requiere en tratamiento más extenso del que aquí es procedente ofrecer, pero no cabe duda de que tanto en la Ley de Economía Sostenible como en la transposición de la Directiva de Servicios que llevan a cabo la LRJPAC y la LRBRL se parte de una visión decimonónica de la realidad administrativa. Cuando la intervención administrativa afecta a la libertad de empresa, pero al mismo tiempo afecta a otros derechos que son reflejo de fines constitucionales (protección de la salud; derechos ambientales, etc), no cabe establecer una preeminencia de la libertad de empresa basada en el principio de proporcionalidad.

Por el contrario, todos los titulares de derechos afectados por la relación jurídico-pública deben gozar de las mismas posibilidades en el procedimiento administrativo y en la tutela judicial efectiva. La valoración que muchas normas hacen de los derechos de quienes se oponen a una instalación o al establecimiento de una actividad es incompatible con un moderno Estado de Derecho. Confundir el respeto de los derechos de los demás con "trabas administrativas" es un craso error.

c) El legislador también está obligado a distinguir las figuras que crea. La ley de procedimiento debería distinguir claramente entre la comunicación previa y la declaración responsable o, simplemente, reducir las dos denominaciones a una sola categoría.

Desde luego ni la LRJPAC ni la LRBRL establecen distinción de régimen jurídico entre ambas categorías.

\section{D) El plan como forma específica de la actividad administrativa}

Sorprende también la ausencia de cualquier mención en el Proyecto de Ley al Plan como figura independiente del acto administrativo o de las disposiciones de carácter general.

Algunos de los males que aquejan al tratamiento jurídico de los planes ambientales y urbanísticos tienen su causa en la ignorancia de las peculiaridades de una figura que no es reductible a la disposición de carácter general o al acto administrativo.

El papel central del plan en el Derecho ambiental y en el urbanístico justificaría que una ley de procedimiento se ocupara de los rasgos esenciales de esta figura y de las peculiaridades de su régimen jurídico.

Asimilar pura y simplemente el plan a una norma, como hace la jurisprudencia, no resuelve los numerosos problemas que plantea el hecho de que el plan no contiene solo regulaciones abstractas basadas en supuestos de hechos hipotéticos, sino que contiene, ante todo, proyectos de obras y reconocimiento de derechos subjetivos de la propiedad. Todo ello puede tener reflejo tanto en el procedimiento de elaboración, como en el de derogación y anulación del plan, que no se resuelvan identificando el plan con una norma jurídica general y abstracta.

\section{E) El contrato por el que se ejerce potestades administrativas}

En los estudios previos a la reforma de la ley 30/1992 (Ley 4/1998) se discutió la oportunidad de que una ley de procedimiento contuviera una regulación completa del convenio o contrato administrativo, en virtud del cual, la Administración en lugar de actuar unilateralmente en el ejercicio de su potestad, acuerda con el interesado los términos concretos en que se aplica el ordenamiento jurídico.

Finalmente en aquella ocasión, el legislador se limitó a regular la tradición convencional del procedimiento, y esto es lo que repite el PLPA, dejando sin contestar los numerosos interrogantes, que los convenios plantean, en

$3 \quad$ Vid. Rebollo Puig, M.: “El repliegue de las autorizaciones y la articulación de alternativas. En especial la tutela de los terceros perjudicados por actividades privadas ilegales", en Soriano García, (Dir.): Por el derecho y la libertad. Libro homenaje al Profesor Juan Alfonso Santamaría Pastor, Vol. II, lustel, Madrid 2014, págs. 1991-2017; BAÑO LEÓN, J.M.: "Declaración responsable y derechos de terceros. El lado oscuro de la llamada «buena regulación»", REDA, n 167, Oct/Dic 2014. 
orden a la exigencia de obligación, o a la aplicación del régimen de recisión de oficio, y a la responsabilidad derivada de cumplimiento ${ }^{4}$.

En otro orden de cosas, resulta claro que una ley de procedimiento debiera responder al interrogante de si debe hacerse un tratamiento básico del contrato comprendiendo tanto el ejercicio de potestades por la Administración como los supuestos en que esta actúa como demandantes de bienes y servicios (contratos administrativos) o, por el contrario, debiera mantenerse separada la legislación contractual pública entendida en el sentido antes expuesto y los contratos o convenios cuyo objeto es el ejercicio de una potestad pública.

\section{3.- La privatización del procedimiento administrativo y la figura del responsable del procedimiento}

En 1958 a nadie se le habría ocurrido que pudiera haber procedimientos administrativos en mano privada. La relación de los privados con la gestión se limitaba al contrato de servicios para aspectos puntales, de ahí la tradicional prohibición de que por contrato se transfiera potestades administrativas (actualmente art. 301.1 LCSP).

En 2015, contamos con una amplia experiencia de procedimientos administrativos que se gestionan por empresas de servicios. Tanto en el ámbito de la recaudación tributaria como en sectores enteros de la policía administrativa (véase, por ejemplo, las Confederaciones Hidrográficas) cada vez es más frecuente que no sea la Administración quien, de facto, gestiona el procedimiento, sin que lo hagan empresas privadas.

El derecho administrativo ofrece también otros ejemplos en el ámbito urbanístico y ambiental. La mayoría de planes no se redactan por los técnicos municipales sino por empresas privadas que son los que formula los planes y contestan las alegaciones, limitándose los técnicos de la Administración a ratificar los estudios y opiniones privadas.

Esto plantea numerosos problemas, para los que el Derecho Administrativo no ha ideado todavía soluciones. Por ejemplo, la separación entre el tratamiento privado de la información y la responsabilidad administrativa; el acceso de terceros a la información o, más simplemente, la transparencia entre lo que es el ámbito de la decisión administrativa y el criterio puramente experto de los técnicos.

Una nueva ley de procedimiento debería ocuparse de estos asuntos estableciendo un mínimo de garantías públicas en el control efectivo de las decisiones y cautelas en el tratamiento de la información. Desgraciadamente, ante la inexistencia de regulación administrativa, es el Derecho Penal el que "regula" ex post estas intervenciones privadas al definir los límites del delito de tráfico de influencias o el de negociaciones prohibidas a los funcionarios públicos.

No estamos hablando aquí ni de desregulación ni de autorregulación; estamos tratando de la utilización del sector privado para el cumplimiento de funciones típicamente administrativas, respecto de las cuales, el ciudadano debería tener ciertas garantías de trato objetivo. Cuáles son las responsabilidades mínimas de la información, quién y cómo debe tener acceso a la información, cuál es la relación entre el contratista y el órgano administrativo que formalmente no puede quedar al arbitrio de cada pliego de condiciones y a la directriz última del Derecho Penal. En la administración en masa, con procedimientos reglados los problemas pueden ser menores. En los procedimientos con un amplio margen de discrecionalidad o en los procedimientos sancionadores, el deslinde entre la competencia de la Administración y los servicios privados debe ser visible en una ley de procedimiento administrativo a la altura de nuestro tiempo.

Resulta claro que el interesado en el procedimiento tiene derecho a conocer quién es el responsable del procedimiento y a exigir un trato objetivo. Por eso, resulta una vez más sorprendente que el PLPAC no haya innovado nada al respecto, pese a las valiosas experiencias del Derecho Comparado, de las que se ha beneficiado el proyecto de Código RENEUAL del Procedimiento Administrativo de la Unión Europea, un notable documento de trabajo elaborado a instancias del Parlamento Europeo5.

\section{IV.- CONCLUSIÓN}

La reforma de la Ley 30/1992, en los términos en que se propone, parece innecesaria y peligrosa.

Innecesaria, porque el objetivo de una Administración electrónica no exige, en absoluto, el desdoblamiento de la actual ley en dos distintas, con un reparto de materias poco coherente y que dificultará el manejo de preceptos de uso diario por los operadores jurídicos. En particular, la separación entre los aspectos procedimentales y

4 BAÑO LEÓN, J.Ma.: “Terminación convencional del procedimiento", en Jornadas de Estudio sobre la reforma de la Ley 30/1992. Jornadas celebradas en Sevilla los días 23 y 24 de febrero de 1997, MAP/BOE, Madrid, 1997.

5 Vid. MIR/SCHNEIDER/HOFMANN/ZILLER (Dir.): Código RENEUAL de procedimiento administrativo de la Unión Europea, INAP, Madrid, 2015. 
sustantivos de la responsabilidad extracontractual y de la potestad sancionadora se compagina mal con una regulación sistemática y fácilmente accesible en esas dos materias centrales del Derecho Público. Por otra parte, ya se ha dicho que el cambio tecnológico que supone pasar de una cultura de papel a una electrónica no muta la naturaleza de la relación entre la Administración y los ciudadanos. La mayor garantía de que la Administración electrónica no influya en un recorte práctico de los derechos, no se juega tanto en la ley sino en los medios técnicos puestos a disposición de los ciudadanos para que la información sea fácilmente accesible e inteligible por cualquier persona que sepa leer y escribir.

Se trata también de una propuesta peligrosa, en cuanto expande desproporcionadamente potestades de la Administración que hasta ahora eran objeto de una interpretación restrictiva, fiada sobre todo a las leyes especiales. La construcción de un deber general de colaboración con la Administración o la delirante expansión de la potestad administrativa para imponer medidas provisionales seguramente no ha estado en el ánimo de los autores de la propuesta. Pero una cosa son las intenciones y otras los resultados de las acciones. $Y$ ateniéndonos a los proyectos de ley presentados en el Congreso de los Diputados, el resultado es decepcionante, como, por lo demás, subrayan todas las colaboraciones que figuran en este número de la revista.

Como se ha tratado de demostrar, estos proyectos no abordan los problemas dogmáticos y prácticos que requeriría una nueva ley de procedimiento. Mientras se decida mantener la benemérita estructura de la ley de 1958 , lo mejor es no tocarla. Experimentos como el que aquí sumariamente hemos comentado, deberían estar desterrados de cualquier acción de gobierno, pues no tiene sentido hacer una reforma aparentemente de gran calado, para dejarlo todo prácticamente igual, pero empeorando sustancialmente la posición jurídica de los ciudadanos ante la Administración, en algunos extremos no menores. 